\title{
DE CAMINO HACIA LA UNIDAD ALEMANA. CRONOLOGÍA DE LOS ACONTECIMIENTOS
}




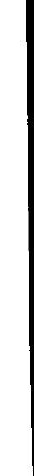




\section{DE CAMINO HACIA LA UNIDAD ALEMANA. CRONOLOGÍA DE LOS ACONTECIMIENTOS (*)}

1989

A partir de julio Refugiados de la RDA (República Democrática Alemana) en las representaciones alemanas de BerlínEste, Budapest y Praga.

Desde septiembre Fuga de $\mathbf{5 0 . 0 0 0}$ habitantes de la RDA a través de Hungría hacia la República Federal de Alemania.

10 septiembre El Canciller Federal Kohl agradece al Gobierno húngaro la decisión de permitir el viaje de salida de Hungría a alemanes procedentes de la RDA.

25/29 septiembre Conversaciones del ministro federal de Relaciones Exteriores con sus homólogos de la Unión Soviética, RDA, Polonia, Hungría y la CSSR (Checoslovaquia). Tema: viaje de salida de refugiados procedentes de la RDA.

30 septiembre Unos 6.000 refugiados de la RDA en la Embajada alemana en Praga pueden partir hacia la República Federal de Alemania.

Primeros octubre Viaje de partida de unos 1.500 refugiados de la RDA en la Embajada alemana en Varsovia.

7 octubre $\quad$ Festividades del 40 Aniversario de la RDA. Miles de personas se manifiestan contra la dictadura del Partido Socialista Unificado de Alemania (SED). Hay intervenciones de la policía.

(*) International Press. 
9 octubre

18 octubre

4 noviembre

7 noviembre

9 noviembre

10 noviembre

13 noviembre

22 noviembre

28 noviembre

1 diciembre

4 diciembre

3 y 6 diciembre
100.000 personas en la "demostración de lunes" en Leipzig, con el grito: "Nosotros somos el pueblo". Siguen más grandes manifestaciones en otras ciudades.

El Secretario General del SED, Erich Honecker, pierde sus cargos tras 18 años en el poder. Le sucede Egon Krenz.

Aproximadamente un millón de personas acuden en el Berlín-Este a la mayor manifestación de protesta en la historia de la RDA.

Dimite el Gobierno de la RDA.

Apertura del "Muro de Berlín» y otros pasos fronterizos hacia la República Federal de Alemania.

El Canciller Federal Helmut Kohl informa de su viaje a Polonia $y$, junto con otros políticos, habla a los berlineses frente al Ayuntamiento de Schoneberg y junto a la iglesia votiva "Gedachtniskirche" en BerlínOeste.

Elección de Hans Modrow (SED) como nuevo Presidente del Consejo de Ministros de la RDA.

El Canciller Federal Kohl hace una declaración ante el Parlamento Europeo en Estrasburgo sobre los acontecimientos en la RDA.

Declaración de Gobierno del Canciller Federal Helmut Kohl ante el Bundestag Alemán (Parlamento Federal) sobre superación de la división de Alemania y de Europa.

La Cámara Popular (Volkskammer) de la RDA borra del texto de la Constitución la pretensión de liderazgo del SED (Partido Socialista Unificado de Alemania).

Cumbre de la OTAN en Bruselas: el Presidente Bush informa sobre su reunión con el Presidente Gorbachov, en la cual fue tema primordial la cuestión alemana.

El Secretario General del SED, Egon Krenz, dimite de todos sus cargos en el Partido y Estado. 
7 diciembre

8/9 diciembre

16/18 diciembre

19/20 diciembre

22 diciembre

24 diciembre
Empiezan las conversaciones de "Mesa Redonda" entre los partidos gubernamentales y la oposición en la RDA. Anuncio de elecciones libres.

Consejo Europeo en Estrasburgo: los jefes de Estado y de Gobierno de la Comunidad Europea declaran que la unificación de Alemania debe hacerse en consonancia con el Acta Final de Helsinki, y encauzarse en la integración europea.

El Canciller Federal Helmut Kohl encomia en Budapest la política húngara de reforma, como condición previa para la Revolución pacífica en la RDA.

El Canciller Federal Helmut Kohl mantiene conversaciones en Dresde con el ministro-presidente Modrow sobre posibilidades de desarrollo de las relaciones entre ambos Estados alemanes, y habla a los ciudadanos de Dresde frente a la iglesia «Frauenkirche».

Apertura de la Puerta de Brandeburgo en presencia del Canciller Federal Kohl, ministro-presidente Modrow y otros políticos de los dos Estados.

Supresión del visado obligatorio y del cambio obligatorio de divisas para viajeros de la República Federal de Alemania y Berlín-Oeste a la RDA.

1990

4 enero

El Canciller Federal Kohl y el Presidente Mitterrand hablan en la reunión informal de Latché sobre la evolución en Alemania y Europa.

10 febrero

El Canciller Federal Kohl y el ministro de Relaciones Exteriores, Genscher, se reúnen en Moscú con el Secretario General Gorbachov, el cual asegura a los alemanes que podrán vivir en un Estado.

13/14 febrero

Ministro-presidente Modrow en Bonn. El Canciller Federal Kohl propone negociaciones sobre unión económica y monetaria. 
14 febrero

15 febrero

24/25 febrero

18 marzo

19 marzo

5 abril

12 abril

19 abril

$25 / 26$ abril
Los ministros de Relaciones Exteriores de las Cuatro Potencias Vencedoras y de ambos Estados alemanes acuerdan emprender conversaciones "Dos + Cuatro" sobre la unidad alemana.

El Canciller Federal Kohl informa al Presidente Mitterrand en París sobre su conversación con el Presidente Gorbachov y actual evolución en Alemania.

El Canciller Federal Kohl habla con el Presidente Bush en Camp David: también para la Alemania unida son de importancia fundamental la liga de seguridad entre Europa y Norteamérica y la amistad con EE.UU.

Primeras elecciones libres en la RDA. Victoria de la "Alianza pro Alemania", formada por la CDU (Unión Cristiano-Demócrata), Despertar Democrático y Unión Social Alemana.

El Canciller Federal Kohl destaca en la Conferencia Económica de la CSCE (Conferencia de Seguridad y Cooperación en Europa) que la unificación de Alemania debe realizarse de acuerdo con sus vecinos del Oeste y del Este.

Sesión constituyente de la primera Cámara Popular libremente elegida de la RDA. Su presidenta electa, Sabine Bergmann-Pohl, médica, desempeña también la función de jefe de Estado de la RDA.

Por primera vez en su historia la Cámara Popular de la RDA elige un Gobierno democrático: la gran coalición gubernamental compuesta por la «Alianza pro Alemania", los liberales y socialdemócratas (SPD); Lothar de Maizière es elegido ministro-presidente de la RDA.

Declaración de Gobierno de de Maizière con pronunciamiento en pro de la unidad alemana.

Consultas germano-francesas: intercambio de opiniones entre el Canciller Federal Kohl y el Presidente Mitterrand sobre la marcha del proceso de unificación alemana. 

Europea celebran en una sesión especial en Dublín la unificación de Alemania y preparan la incorporación de la RDA a la Comunidad Europea para la fecha de realización de la unidad alemana.

5 mayo

Los ministros de Relaciones Exteriores de ambos Estados alemanes, Gran Bretaña, Francia, Ios EE.UU. y la URSS, se reúnen en Bonn por primera vez para tratar sobre los aspectos exteriores de la unidad alemana (reunión "Dos + Cuatro").

6 mayo

16/17 mayo

18 mayo

8 junio

10 junio

17 junio

21 junio
Elecciones municipales en la RDA: la CDU sigue siendo el partido más fuerte.

El Canciller Federal Kohl informa en Washington al Presidente Bush sobre pasos ulteriores hacia la unidad alemana, y le agradece su apoyo en las conversaciones "Dos + Cuatro", especialmente respecto al acceso a la plena soberanía.

El Gobierno Federal y el Gobierno de la RDA firman en Bonn el Tratado Interestatal de Unión Monetaria, Económica y Social de la República Federal de Alemania y la RDA.

El Canciller Federal Kohl y el Presidente Bush confirman en Washington que es indispensable la plena pertenencia de la Alemania unida a la OTAN.

Las Tres Potencias Occidentales renuncian a sus reservas respecto a la representación de Berlín en el Bundestag y Bundesrat (Parlamento y Consejo Federales); desde el 21 de junio los representantes berlineses ejercen su pleno derecho a voto en las dos Corporaciones parlamentarias federales.

El Bundestag Alemán y la Cámara Popular de la RDA conmemoran en sesión conjunta en Berlín-Este la Rebelión Popular del 17 de Junio de 1953 en la RDA.

El Bundestag y la Cámara Popular de la RDA aprueban sendas resoluciones de igual texto sobre la frontera de la Alemania unida con Polonia; proclaman su voluntad de confirmar definitivamente el trazado de la frontera mediante el correspondiente tratado juridico-internacional. 
21 junio

22 junio

25/26 junio

27 junio

1 julio

5/6 julio

9/11 julio

14/16 julio

17 julio
El Bundestag aprueba el Tratado Interestatal sobre establecimiento de la unión monetaria, económica y social entre la República Federal de Alemania y la RDA.

El Bundesrat aprueba dicho Tratado Interestatal.

El Canciller Federal Kohl informa al Presidente Mitterrand en Assmannshausen sobre el estado del proceso de unificación alemana.

Consejo Europeo en Dublín: los jefes de Estado y de Gobierno celebran la conclusión del Tratado Interestatal entre ambos Estados alemanes, que agiliza la incorporación de la RDA a la CE.

El Gobierno Federal y el de la RDA aprueban la supresión de controles de personas en la frontera interalemana para el 1 julio 1990.

Entra en vigor la unión monetaria, económica y social de la República Federal de Alemania y la RDA. Se suprime el procedimiento de acogida asistencial de trasladados de la RDA.

Los jefes de Estado y de Gobierno declaran en la Conferencia cumbre de la OTAN en Londres que la Alemania unida será factor indispensable de estabilidad en la Alianza Atlántica.

Los jefes de Estado y de Gobierno participantes en la Cumbre Económica Mundial de Houston celebran la unificación de Alemania como muestra patente de la autodeterminación y del Derecho, y como aporte a la estabilidad de Europa.

En su visita a la URSS el Canciller Federal Kohl se puso de acuerdo con el Presidente Gorbachov en que la Alemania unida alcanzará su plena soberanía, podrá decidir libremente su futura pertenencia a alianza, y sus fuerzas armadas quedarán reducidas a 370.000 hombres. La Unión Soviética retirará sus fuerzas armadas de la RDA en 3 hasta 4 años.

Los seis ministros de Relaciones Exteriores ("Reunión Dos + Cuatro") y el ministro de Exteriores de Polonia se pusieron de acuerdo en París respecto a los 
22 julio

2 agosto

23 agosto

31 agosto

12 septiembre

19 septiembre

20 septiembre

21 septiembre

$1 / 2$ octubre principios para la regulación de fronteras de la Alemania unida. En lugar de un tratado de paz, los participantes acordaron que firmarían un Documento sobre Alemania, donde se regulen todas las cuestiones relativas al restablecimiento de la soberanía; una vez firmado por los participantes, el documento será presentado en noviembre de este año a la ConferenciaCSCE para su aprobación.

La Cámara Popular aprueba la Ley de Implantación de Lander (Estados federados) en la RDA. Se constituyen cinco Lander.

Firma de un Tratado Electoral entre la República Federal de Alemania y la RDA, donde se regulan las modalidades de las elecciones conjuntas alemanes que han de tener lugar el 2 de diciembre de 1990. A tal efecto regirá una cláusula-tope unitaria del 5 por ciento de los votos emitidos en un territorio electoral unitario, con la posibilidad de hacer combinaciones de listas.

La Cámara Popular de la RDA acuerda incorporarse a la República Federal de Alemania el 3 de octubre de 1990.

Firma del Tratado de Unificación entre la República Federal de Alemania y la RDA en el "Kronprinzenpalast" (Palacio del Príncipe Heredero), en Berlín, por el ministro federal del Interior, Dr. Schauble, y el subsecretario de la RDA, Krause.

Terminan las conversaciones de ministros de Relaciones Exteriores en Moscú. Se firma el Tratado «Dos + Cuatro".

La Cámara Popular (Volkskammer) de la RDA aprueba el Tratado de Unificación.

El Bundestag Alemán aprueba el Tratado de Unificación.

Deliberación final del Bundesrat (Consejo Federal) sobre el Tratado de Unificación.

Firma del Documento de Suspensión de los Derechos de las Cuatro Potencias, en Nueva York. ReuniónCSCE de ministros de Relaciones Exteriores en Nueva York. 
3 octubre

4 octubre

12 octubre

14 octubre

3 noviembre

19/21 noviembre

2 diciembre
La RDA se incorpora al ámbito de vigencia de la Ley Fundamental según su artículo 23. Establecimiento de cinco nuevos Lander en el territorio de la anterior RDA (Brandeburgo, Mecklemburgo-Pomerania, Sajonia, Sajonia-Anhalt y Turingia).

Primera reunión del Bundestag en el edificio del Reichstag berlinés, junto con los 144 diputados enviados por la Cámara Popular de la anterior RDA.

Juramento de los nuevos ministros federales; Declaración de Gobierno del Canciller Federal.

Reunión del Bundesrat participando por primera vez los delegados de los cinco nuevos Lander (Estados federados), sólo con voz.

Elecciones de Land en los cinco Lander del territorio de la anterior RDA.

Cumbre especial de jefes de Estado y de Gobierno de la Comunidad Europea en Roma.

Conferencia-cumbre especial de jefes de Estado y de Gobierno de la CSCE en París sobre la futura arquitectura de Europa.

Primeras elecciones conjuntas alemanas para el Bundestag Alemán (Parlamento Federal). 